\title{
Software Development Process Ambidexterity and Project Performance: A Coordination Cost-Effectiveness View
}

\author{
Karl Werder, Ye Li, Alexander Maedche, and Balasubramaniam Ramesh
}

\begin{abstract}
Software development process ambidexterity (SDPA) is the ability to demonstrate both process alignment and process adaptability simultaneously. Realizing process ambidexterity has recently been suggested as an effective approach to improving the performance of software development (SD) projects. To understand the mechanisms underlying the effects of ambidexterity, we focus in this study on the mediating effects of coordination, one of the most important activity in SD projects. Specifically, we hypothesize a mediating effect of coordination costs and coordination effectiveness on the relationship between SDPA and project performance. We conducted a quantitative study involving 104 SD projects across 10 firms to test the model. The results strongly suggest that the positive relationship between SDPA and project performance is negatively mediated by coordination costs and positively mediated by coordination effectiveness. We validate our research model with a case study in an organization employing several hundred IT professionals and derive several practical implications on this basis.
\end{abstract}

Index Terms - ambidexterity, coordination, coordination cost, cost-effectiveness, project performance, software development

\section{INTRODUCTION}

A MBIDEXTERITY is an important organizational capability describing the simultaneous achievement of two seemingly conflicting goals [28], [34], [49]-[51], [71]. Such conflicting goals typically involve tradeoffs that need to be balanced (e.g., effectively managing incremental and revolutionary changes [105], being aligned and adaptable in project management activities [34]) so that an organization can be more successful [34], increase performance (e.g., [44]), and be more innovative (e.g., [2]).

Scholars from different disciplines, such as organizational sciences, strategic management, information systems, and software engineering have investigated ambidexterity. For example, research on organizational ambidexterity investigates business learning vs. strategic learning [109] and efficiency vs. innovation [37], [108]. From a strategic management perspective, scholars investigate cost reduction vs. revenue expansion [65], and inter-organization systems research compares contractual governance vs. relational governance approaches when outsourcing information technology [18]. In software development (SD), the ambidextrous capability to demonstrate process alignment and process adaptability simultaneously is most frequently investigated [7], [48], [51], [82]. Other

- K. Werder is with the University of Cologne, Pohligstr. 1, 50969 Cologne, Germany.E-mail:werder@wiso.uni-koeln.de.

- Y. Li is with the University of Mannheim, L15, 1-6, 68131 Mannheim, Germany. E-mail: christianly@gmail.com

- A. Maedche is with the Institute of Information Systems and Marketing (IISM), Karlsruhe Institute of Technology (KIT), Fritz-Erler-Str. 23, 76133 Karlsruhe, Germany. E-mail:alexander.maedche@kit.edu.

- B. Ramesh is with the Department of Computer Information Systems, Robinson College of Business, Georgia State University, 55 Park Pl. NE, 30303 Atlanta, USA. E-mail:bramesh@gsu.edu.

Please note that all acknowledgments should be placed at the end of the paper, before the bibliography (note that corresponding authorship is not noted in the affiliation box, but in the acknowledgment section). examples include the patch development vs. feature-request development [100], and use of formal controls vs. informal controls during SD [36], [102].

We understand software development process ambidexterity (SDPA) as the capability to achieve process alignment and process adaptability simultaneously (see [13], [34], [82]). While SDPA is rapidly gaining attention in empirical software engineering research, most prior studies have investigated a direct effect of SDPA on SD project performance (e.g., [2]). Yet, empirical studies on the effect of SDPA on SD project performance are sparse and report mixed results. On the one hand, a prior study reports that global SD teams are more successful when enhancing both process alignment and adaptability in contrast to enhancing only one type of the SD process capabilities [82]. On the other hand, another study finds a negative interaction effect of process standardization and process agility, leading to poorer performance in SD projects [49].

Furthermore, only a few studies investigate a more complex relationship between SDPA and SD project performance (e.g., [52]). Hence, we lack a deep understanding of the underlying mechanisms in this relationship [43], [89]. Given the importance of coordination within SD projects [12], [21], [42] and its effect on project performance [32], [63], [69], [85], [107], we investigate the effect of coordination within the relationship between SDPA and project performance. While one prior study investigated the mediating role of coordination on the relationship between project and process characteristics toward SD success [52], we extend this work by adopting a coordination cost/effectiveness perspective and hence, investigate the role of coordination in greater depth. In addition, we distinguish between project effectiveness and project efficiency, providing a closer examination of the mechanisms underlying the functions of SDPA. We draw on the theory of dy- 
namic capability [74], [98], [99] to propose a model that investigates and explains the effects of SDPA on SD project effectiveness and project efficiency. We suggest that SDPA fosters coordination [70] and, therefore, coordination forms a mediating factor between SDPA and SD project performance. Specifically, we formulate the following research question:

$\mathbf{R Q}$. What are the mediating effects of coordination costs and coordination effectiveness on the relationships between SDPA and SD project effectiveness and efficiency?

Our research provides three main theoretical contributions concerning SDPA and its effects on SD project performance. First, we extend the extant body of literature on project capabilities by using organizational theory to explain the mediating role of coordination on the relationship between SDPA and project performance. Second, we investigate the relationship of SDPA on SD project performance in more depth and distinguish between the project effectiveness and project efficiency. We explain these effects through a partial mediation of coordination using a cost/effectiveness view. Therefore, we answer prior calls for more research on the ambidexterity-performance relationship [43], [89]. Third, we extend the body of empirical studies on ambidexterity with quantitative results using a large sample of 214 responses from practitioners forming 104 project responses. Our practical contribution helps managers to understand the different performance implications of coordination cost/effectiveness.

\section{Contextual AmBideXterity}

The literature on ambidexterity presents three different types of ambidexterity: structural, temporal, and contextual ambidexterity. These types differ in terms of achieving two seemingly conflicting goals. First, structural ambidexterity refers to the creation and maintenance of spatially separated sub-units (e.g., business units, groups), each of which pursues one of the conflicting goals [105]. Ambidexterity is achieved at a higher management level, at which the sub-units are integrated [71].

Second, temporal ambidexterity suggests that a sub-unit pursues one goal at a time (e.g. exploration and exploitation), switching between goal [28], [104]. Thus, ambidexterity is achieved by practicing the temporal switching over time, also referred to as sequential alternation [10] as it entails temporally moving between the two goals (e.g., exploration and exploitation). Sequential alternation highlights the process of cycling through periods of exploration and exploitation [17].

Third, contextual ambidexterity refers to a sub-unit's capability to pursue conflicting goals simultaneously [34]. Structural and temporal ambidexterity require investments and efforts to establish and maintain separate structures, as well as coordinate the separate structures at a higher level or over time [55]. In contrast, contextual ambidexterity requires investments and efforts to foster an appropriate organizational context that supports paradoxical activities at the sub-unit or individual level [34]. Contextual ambidexterity (also referred to as behavioral integration [10]) — "the behavioral capacity to simultaneously demonstrate alignment and adaptability across an entire business unit" [34] — presents an alternative approach to managing tradeoffs. It requires developing a set of processes or systems that enable and encourage individuals to make their own judgments about how to divide their time between conflicting demands (e.g., for alignment and adaptability) rather than by creating dual structures [105].

Thus, contextual ambidexterity relies on decision making and organizational structures that provide a suitable environment for managing tradeoffs in which an individual manages the conflicting goals, rather than engraining ambidexterity into organizational characteristics [27], [34]. A prior study suggests a typology of different work practices with alternative implications for performance and innovativeness [45]. Other theoretical advances on contextual ambidexterity seek to understand the nomological net of contextual ambidexterity in greater depth. For example, an integrative framework suggests a moderating role of contextual mechanisms on the relationship between a selected dual strategy toward an existing tension or goal conflict [27]. Another study suggests that contextual ambidexterity moderates the relationship between top management team behavioral complexity toward organizational ambidexterity [20].

While theoretical work often focuses on the moderating role of ambidexterity, empirical work finds direct and mediating effects of contextual ambidexterity. One study in the context of inter-organizational relationships shows a significant effect of contextual ambidexterity on relationship performance; the results were drawn from a survey $(\mathrm{N}=314)$ investigating customer-vendor relationships, with key informants from both sides [40]. Furthermore, the findings suggest a mediating effect of contextual ambidexterity within the relationship between coordination structure and performance. In a similar vein, an organizational study $(\mathrm{N}=41)$ investigates the mediating role of contextual ambidexterity between context and performance, finds a significant full mediating effect [34]. However, an in-depth case study $(\mathrm{N}=1)$ suggests that the development of contextual ambidexterity is more complex, requiring a symbiosis between context and content, whereas the symbiosis happens through various processes [67].

\section{Software Development Process AMBIDEXTERITY}

Prior studies introduce different terms regarding SDPA. For example, one study uses the term ambidextrous properties of global software teams when describing the team's use of coping strategies to establish rigor while maintaining flexibility and agility [48]. The study suggests seven coping strategies that enhance ambidexterity within SD. In another study, scholars use and define the term IS development process ambidexterity as "the process capability that simultaneously demonstrates alignment and adaptability in IS development" [49]. Process rigor and standardization are suggested to reflect process alignment, and process agility is suggested to reflect process adaptability. Therefore, the study frames ambidexterity as a higher-level process capability. Later research focuses on the lowerlevel process capabilities of process rigor, process standardization, process agility, and process customizability to investigate their moderating effects on the relationship between task environment complexity and coordination effectiveness [52]. Following prior studies, we understand 
SDPA as contextual ambidexterity (e.g., [67], [82], [102]). We formulate an adapted definition of SDPA as the ability to demonstrate process alignment and process adaptability simultaneously at the SD project level without higher-level integration or over time observation (c.f. [49]-[51]).

Prior research on SDPA mainly leverages qualitative research. For example, to achieve product and process goals, exploitation and exploration capabilities help organizations to benefit from different innovation mechanisms [59]. Batra et al. [7] found in a case study that both alignment and adaptability were needed to achieve project goals in large and distributed $\mathrm{SD}$ projects. Balanced practices related to operational- and relational-focus foster contextual ambidexterity within SD, while mitigating project conflict caused by competing alignment and adaptability goals [82]. Investigating two perspectives of contextual ambidexterity in SD organizations-i.e., an alignment-adaptability perspective and a performance management-social support perspective- - scholars derive principles that guide software managers in building ambidextrous capabilities [67]. Furthermore, a prior study developed the concept of control ambidexterity resulting from bureaucratic and collaborative management styles to improve the management of tensions between the two styles [36].

Few studies take a quantitative approach toward ambidexterity within SD. When investigating SDPA, one study finds a positive interaction effect between process rigor and process agility, while simultaneously reporting a negative interaction effect between process standardization and process agility [49]. Another suggests that SD ambidexterity process-based control mechanisms (e.g., the prescription of techniques and methods) enhance the achievement of project goals and development flexibility, while outcome-based control mechanisms (e.g., by prespecifying desired final and intermediate outcome) impair such objectives [102]. A fit between the collaboration facilities results in productivity gains and the timeliness of the project [97]. In contrast to the abovementioned empirical studies that investigate either an SD project's or an organization's process ambidexterity, a recent study investigates ambidexterity on the artifact level [100]. The study compares the influence of social graph data on the project's success for exploration (feature development) and exploitation (patch development) networks, whereas differences are the result of team formation processes and activity types. Fitting practices and technology that increase cross-site communication help speed up the development process [39].

Despite the growing attention paid to SDPA, empirical studies related to its effects on SD project performance are sparse and existing findings are mixed. For example, prior studies report increased project success as the result of process alignment and adaptability [48], while another study reports a decrease in project performance [49]. Hence, more research is needed to extend the extant empirical literature, to understand mechanisms underlying ambidexterity functions and to investigate the role of coordination in such a nomological net.

\section{Hypotheses Development}

In line with organizational theory and prior studies, we understand SDPA and coordination as dynamic capabilities [8], [27], [70], [74], [94]. Dynamic capabilities have been suggested to explain the competitive advantages of firms and have been defined as "the firm's ability to integrate, build, and reconfigure internal and external competences to address rapidly changing environments" [99]. They are classified into a tripartite of sensing, seizing, and reconfiguring [98], each help organizations to remain competitive in turbulent environments [99].

Dynamic capabilities formulate a higher-order capability that helps to sense, seize, and reconfigure operational capabilities [24], through sensing, learning, integrating, and coordinating capabilities [74]. They often relate to activities such as cross-line business innovation or new product development [70]. In addition to dynamic capabilities, operational capabilities are important to maintain performance, as they support the production of a marketable product [99]. While dynamic capabilities are associated with competitiveness, operational capabilities have a closer association to performance [80]. Operational capabilities help organizations to combine and to utilize resources in functional activities, such as marketing, sales, logistics, and production [24].

Advances in dynamic capabilities investigate conceptualizations and seek to understand dynamic capabilities in greater depth. When proposing a measurable model for dynamic capabilities, one study suggests that sensing opportunities help organizations to learn and integrate new knowledge before reconfiguring its operational capabilities [74]. Others suggest that the nature of a dynamic capability (e.g., ability or process) influences the action of a dynamic capability [94]. Such action is targeted toward an object (e.g., resource or opportunity) and results in some benefit (e.g., performance, competitiveness over time or effectiveness). Ambidexterity as a dynamic capability relates to the productivity dilemma [8], i.e., the ability to address conflicting organizational requirements, such as incremental innovation vs. exploratory innovation.

To avoid overlooking interesting findings due to use of a composite measure, we decompose project performance into project efficiency and project effectiveness, as suggested by prior literature [15], [93], [103]. Project efficiency relates to the use of resources and timeliness of the development project, whereas project effectiveness refers to the software quality and economic success of the software [15], [72].

\subsection{The Effects of SDPA toward Performance}

We propose a direct effect of SDPA toward project performance. The literature presents empirical evidence on the direct effects of ambidexterity toward performance. For example, empirical evidence within SD supports the direct effects of ambidexterity dimensions (process rigor, process standardization, and process agility) toward performance [49]. In a similar vein, a meta-analysis summarizing the results of 17 studies concludes with a significant effect of ambidexterity toward performance [43], whereas contextual factors can influence this relationship. In addition, research on product development teams suggests a direct effect of team abilities toward team outcomes, such as effectiveness and efficiency as a result of aggregating the findings from 38 empirical studies [90]. When focusing on the effect toward project effectiveness, we suggest that alignment reduces the number of errors being made. A reduced number of errors increases 
the software quality. Simultaneously, process adabtability enhances the project teams' ability to innovate and therefore, increases the economic success of the software. Thus, we hypothesize: H1a. SD process ambidexterity positively influences SD project effectiveness.

When focusing on the effect toward project efficiency, we suggest that process alignment leads to economies of scale and therefore, reduces resource demand during SD. Simultaneously, process adaptability enhances the ability to respond to changes. Responding to changes increases flexibility and timeliness of the project. Thus, we hypothesize: H1b. SD process ambidexterity positively influences SD project efficiency.

\subsection{The Effects of SDPA toward Coordination}

We propose a direct effect of SDPA toward coordination. Following the defining elements of dynamic capabilities [94], the nature of dynamic capabilities can be further specified as an ability, enabling device, or capability. Following our definition of SDPA as the ability to demonstrate process alignment and process adaptability simultaneously, we suggest SDPA as the nature of dynamic capability.

Within the context of SD, coordination, i.e., the management of dependencies [62], [66], is an important dynamic capability [74]. Given the high number of dependencies in SD projects, coordination is a central capability [9], [30], [69]. Software components or functions may be developed by different individuals or sub-teams and hence require integration. Subprocesses or activities may have concurrent requirements on the same resources (e.g., experts' or developers' time). The development activities require alignment to historical decisions (e.g., compatibility requirements), standards (e.g., security, usability standards), and customer requirements. Hence, we suggest coordination as the action of dynamic capability [94]. $\mathrm{SD}$ project coordination orchestrates the functional activities of an SD project [74]; thus, SD coordination should be more closely related than SDPA to performance.

Coordination Effectiveness: SDPA improves the project's synchronization of work and sharing of resources, which are essential elements of effective coordination [73], through process alignment. SDPA helps project teams to manage its dependencies [62], such as the sharing of resources, scheduling and synchronization of constraints, or goal selection when accomplishing a task more effectively. Hence, we hypothesize: H2a: SD process ambidexterity positively influences SD project coordination effectiveness.

Coordination Costs: Considering SDPA as the nature of dynamic capability and coordination as the action that changes the use of current resources, the project achieves a certain aim (e.g., higher performance) [94]. SDPA provides the project team the ability to simultaneously demonstrate process alignment and process adaptability. An increase in SDPA also generates more dependencies, which need to be managed, resulting in higher costs. Therefore, we hypothesize: H2b: SD process ambidexterity positively influences $S D$ project coordination cost.

\subsection{The Effects of Coordination toward Performance}

A key focus of this study are the effects of coordination as an important dynamic capability in the context of SD projects, helping project members to manage project dependencies [62], [66]. The coordinating capability helps the project team to integrate tacit and explicit knowledge to improve the costeffectiveness of their development efforts [83]. For example, when implementing process ambidexterity in an SD project, the team needs to coordinate the reconciliation of conflicting team structures, mentalities, development practices, team cultures, and expertise [7], [13]. When investigating the integration of tacit and explicit knowledge, prior research highlights the importance of coordination, suggesting a cost/effectiveness view [83]. The cost/effectiveness view is an established analysis used for evaluating SD projects [4], [22], [54]. The view contrasts the quantifiable outcome (effectiveness) with the costs of resources needed to obtain such an outcome (cost). While acknowledging the significant contributions of prior studies on the mediating role of coordination in SD projects, we find that they tend to focus on either coordination effectiveness [51], [52], [95] or coordination costs [25], [26], but not both simultaneously. Hence, we investigate the effects of coordination effectiveness and coordination costs as two important elements of SDPA.

We find empirical results for the effect of coordination toward performance. While one study of 83 software projects suggests an effect of coordination toward a performance dimension (i.e., software quality) [35], another study of 123 technical teams suggests a direct negative effect of coordination problems toward team performance [30]. In addition, a literature review summarizing empirical evidence provides support for a direct relationship between coordination and outcome variables (i.e., productivity and quality) within SD [68].

Coordination Effectiveness: Coordination is an important dynamic capability within SD projects [74]. Through coordination, the project team is able to manage its dependencies [62], such as the sharing of resources, scheduling and synchronization of constraints, or goal selection when accomplishing a task. Whether team members share their resources fairly influences the level of coordination effectiveness [73]. The effectiveness of coordination as a dynamic capability has different effects on project effectiveness than it has on project efficiency.

We propose a direct effect of coordination effectiveness toward project effectiveness. We suggest coordination optimizes the use of current resources to achieve the aim, i.e., higher levels of performance [94]. In this relationship, the coordination capability helps the project team to reconfigure project resources and routines. In a similar vein, coordination has been suggested to assist the deployment of tasks, activities, and resources to reconfigure operational capabilities [74] and therefore orchestrate individual project resources. The effective use of coordination efforts increases the project's ability to meet initial requirements as well as the ability to respond to changing requirements [68]. This results from the synchronization that is achieved through coordination. Thus, we hypothesize: H3a. SD project coordination effectiveness has a positive effect toward SD project effectiveness.

We propose a direct effect of coordination effectiveness toward project efficiency as well. Additional alignment requires more time of the project members to setup and hold meetings to synchronize efforts and learn about environmental changes. The time invested in these activities help the team to avoid additional cost and efforts that otherwise may result 
from lack of or inadequate coordination. While these coordination efforts may be perceived as additional work in the short-term, it helps the project to manage dependencies and thus, keeping the project within the initial timeline and budget. Thus, we hypothesize: H3b. SD project coordination effectiveness has a positive effect toward SD project efficiency.

Coordination Costs: Coordination costs refer to the time and efforts spent on maintaining communication and coordination links, and exchanging information between interdependent actors [61], [96]. The cost of coordination capability has different effects on project performance. Although implementing SDPA can substantially improve coordination effectiveness, it may also impose significant coordination costs to the development process [50]. As stated by Slaughter et al. [91], every effort that improves software quality should be viewed as an investment and needs to be financially justified. Thus, focusing on only one side of coordination, e.g., its effectiveness or its costs, may produce misleading results [31].

We propose a direct effect of coordination costs toward project effectiveness. Additional coordination provides the project with more resources. Yet, these resources require maintenance and management, which diverts some project resources toward overhead cost, rather than contributing directly to the project delivery. While such increased coordination costs match prior reports about the resource demands of an ambidextrous approach [56], injecting overhead costs into a projects makes it more difficult for the project to react to changing requirements. Hence, we suggest a negative association between coordination costs and project effectiveness. Thus, we hypothesize: H4a. SD project coordination costs has a negative effect toward SD project effectiveness.

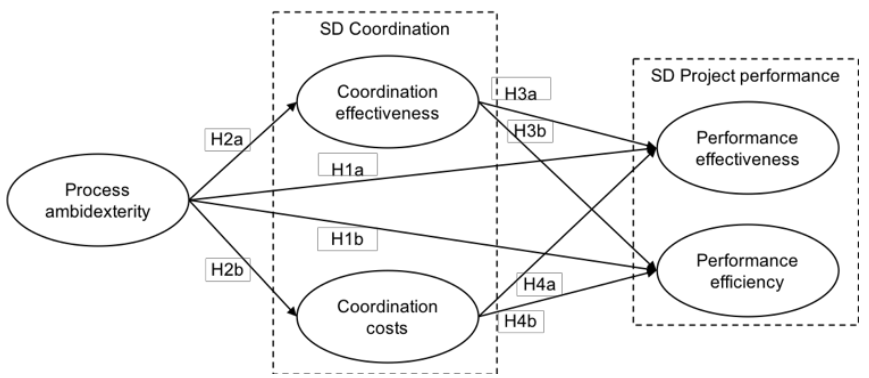

Fig. 1. Research model.

We propose a direct effect of coordination costs toward project efficiency. When more time and resources are spent, the project delivery within budget and on time becomes less likely, suggesting a decrease of project efficiency. Specifically, increased resources and time needed for coordination activities lead to coordination problems that decrease performance [30]. In a similar vein, we suggest a decrease in overall project efficiency as the result of additional time and resources invested into coordination efforts. Higher costs make it more difficult for the project to be delivered within a certain budget and hence have a negative impact onto project efficiency. Since coordination costs are part of the overall project costs, we propose that the higher the coordination costs, the more resources and time are needed for the project. We suggest a negative association between coordination costs and project efficiency. We hypothesize: $\mathbf{H} \mathbf{4 b}$. $S D$ project coordination costs has a negative effect toward SD project efficiency.

The research model summarizes the hypotheses (Figure 1).

\section{Research Method}

\subsection{Research Sampling and Data Collection}

We test our research model using survey data from SD organizations based in the United States and Germany. The survey methodology allows us to collect a larger cross-sectional dataset from practitioners, which was required to test our mediation hypotheses. A research project description explaining the purpose and expected outcomes of the study was sent to 16 software firms through the network of an applied research institute. Ten firms agreed to participate in the study. A customized survey link was sent to a senior executive (e.g., $\mathrm{CEO}$ or $\mathrm{CIO}$ ) in each participating firm via email. The survey was forwarded to a total of 364 $\mathrm{SD}$ project managers and members. To reduce the bias related to retrospective data, we defined valid respondents as those who completed at least one SD project in the respective firm within the past 12 months. After removing invalid and incomplete responses, we retained 214 usable responses from $104 \mathrm{SD}$ projects, resulting in a response rate of $55.2 \%$. Appendix A shows the profile of the participating firms, the respondents, and the SD projects.

\subsection{Non-Response Bias and Key Informant Reliability}

To reduce non-response bias, we provided potential respondents with incentives (including a customized report and a raffle of IT professional books) and sent out multiple reminders during the data collection process [46]. We tested the data for non-response bias by comparing the earlier half of the respondents with the latter half [3], [58] and did not find significant differences between these groups. Thus, non-response bias may not be a significant issue.

Since our unit of analysis is an SD project, we aggregated individual responses to the project level. We used the intraclass correlation coefficient (ICC(1) [41] and aWG [16] to assess the within-group agreement and reliability. ICC(1) can be interpreted as a measure of effect size [11], [47], and indicates the extent to which individuals' responses are influenced by their group membership. For sub-dimensions of process alignment, process adaptability, coordination effectiveness, coordination costs, project efficiency, project effectiveness, and task routineness, all the calculated ICC(1) values are above 0.25 , suggesting a strong effect of group membership [47]. aWG is a newly developed index of within-group agreement that mitigates the limitations of the conventional rWG index, such as scale dependency and sample size dependency. The aWG indices of all the main variables were above 0.78 , suggesting strong within-group agreement [47]. Thus, we used the mean of individual responses to represent the project's response. Aggregating individual responses to the project level improved the measurement reliability at the project level and mitigated a potential key informant bias. 


\subsection{Construct Measurement}

We used multiple items on a seven-point Likert scale to measure process alignment, process adaptability, coordination effectiveness, coordination costs, project efficiency, and project effectiveness to improve reliability and reduce potential measurement errors [23]. A pilot study involving 13 SD professionals generated qualitative feedback that was used to evaluated and improve the questionnaire design. The feedback resulted in minor changes to the questionnaire design and confirmed the plausibility and understandability of the questionnaire. The measurement instruments are presented in Appendix B.

SDPA. We measured SDPA as a single construct comprising the multiplicative interaction of process alignment and adaptability [34]. This conceptualization suggests process alignment and adaptability as two interrelated but non-substitutable dimensions of ambidexterity [34]. Process alignment constitutes of process rigor and standardization. While process rigor reflects a formal SD, process standardization measures the consistency of the applied method and techniques during development [49]. Process adaptability assesses the ability to sense and respond to changing requirements during development. Both process alignment and adaptability form SDPA measurement.

Process alignment was a composite of two aspects: process rigor (Cronbach's $\alpha(\mathrm{CA})=0.76$, composite reliability $(\mathrm{CR})=0.85$, average variance extracted $(\mathrm{AVE})=0.58$, $\mathrm{ICC}(1)=0.42, \mathrm{aWG}=0.85)$ and process standardization $(\mathrm{CA}=$ $0.91, \mathrm{CR}=0.94, \mathrm{AVE}=0.78, \mathrm{ICC}(1)=0.55, \mathrm{aWG}=0.88)$, consisting of four items each (adopted from [49], [51]). We measured process adaptability $(\mathrm{ICC}(1)=0.51, \mathrm{aWG}=0.93)$ as a formative construct comprising nine items (adopted from [14]).

Coordination effectiveness. We assess coordination effectiveness through coordination efforts within the team related to tasks, work outcome, and resources. We measured coordination effectiveness with an instrument that we adapted from Pavlou and El Sawy [73] $(\mathrm{CA}=0.83, \mathrm{CR}=0.87, \mathrm{AVE}=0.54$, $\operatorname{ICC}(1)=0.32$, aWG $=0.91$ ), which refers to the extent to which the project team's tasks fit together, outputs were synchronized, output were useful to others, resources were allocated appropriately, resources were shared fairly, and the team was well-coordinated.

Coordination costs. We assessed the effort and time invested in coordination of a project to understand its costs. Adapted from Tanriverdi et al. [96], we measured coordination costs with five items. To assess the reliability and validity of the self-reported coordination costs scale, we asked the respondents to report the percent of project work time spent on coordination activities. Approximately $75.0 \%$ of the projects spent $10-30 \%$ of the project work time on coordination activities. This measure is strongly correlated with the perceived coordination costs $(\mathrm{r}(102)=0.260, \mathrm{p}=0.008)$, indicating acceptable reliability and validity of the self-reported measure of coordination costs $(\mathrm{CA}=0.78, \mathrm{CR}=0.85, \mathrm{AVE}=0.53, \mathrm{ICC}(1)=$ $0.28, \mathrm{aWG}=0.89$ ).

SD project effectiveness. We measured project effectiveness as a composite of two aspects: the extent to which delivered software products or services meet pre-specified customer requirements and needs [53], [88] and the extent to which the delivered software products or services incorporate changes in the requirements during the development process [102]. In a similar vein to the conceptualization of SDPA, a project needs to manage both, meet requirements and incorporate changes to be effective. Four items were used to measure whether the pre-specified requirements were met $(\mathrm{CA}=$ 0.87, $\mathrm{CR}=0.91, \mathrm{AVE}=0.73, \mathrm{ICC}(1)=0.33, \mathrm{aWG}=0.85)$ and three were used to measure whether the changes were incorporated into the requirements $(\mathrm{CA}=0.82, \mathrm{CR}=0.89, \mathrm{AVE}=0.74$, $\mathrm{ICC}(1)=0.48, \mathrm{aWG}=0.78$ ) (adopted from [53], [102]).

SD project efficiency. Based on Shenhar et al. [88], we measured SD project efficiency with two items $(\mathrm{CA}=0.84$, $\mathrm{CR}=0.92, \mathrm{AVE}=0.85, \mathrm{ICC}(1)=0.67, \mathrm{aWG}=0.80)$ : the extent to which a project was completed on time and on budget. To check the reliability and validity of the self-reported measures, we also collected partial data on the actual completion time and actual project spending. Ninety-two (92) projects reported their planned and actual completion time, and 25 reported their planned and actual project spending. The actual delay and the percent of budget overrun were taken as measures of the actual project efficiency. The actual project efficiency measures are strongly correlated with the self-reported measures of project efficiency: on time $r(90)=0.43, p<$ 0.001 ; on budget $\mathrm{r}(23)=0.602, \mathrm{p}=0.001$, indicating acceptable reliability and validity of the self-reported measures.

Control variables. We measured a variety of team and task characteristics as potential control variables. Prior studies suggest that distribution may influence a team's coordination process and performance [30], [31], [48], [52]. Thus, we measured an SD project's team size as the number of people working on the project. We measured team distribution with the number of cities and time zones the team members were in and the maximum clock time difference among all the team members. We applied log transformation to the team size and the number of cities and time zones to correct skewness and kurtosis. To address the influence of task uncertainty on the SD process and performance [5], we measured task routineness with three items (e.g., people involved in that project did similar tasks everyday) [84].

We control for firm size as an influential variable [19], [29], [56], [76]. Following prior studies [19], [29], we assessed firm size by considering the firm's total number of full-time employees and its total asset in the last financial year. We distinguished between "smaller firms" (51-1000 employees), and "larger firms" (1000+ employees). On average, the smaller firms had 323 employees and \$27.5 million in assets in the financial year of 2012, whereas the larger firms had 26.8 thousand employees and $\$ 13.7$ billion in assets in the same financial year. In our sample, $57.7 \%$ of the projects were completed in the smaller firms, and $42.3 \%$ were completed in the larger firms. We coded the smaller firms " 0 " and the larger firms " 1 " in the data analysis.

\subsection{Assessment of the Measurement Models}

For multi-item reflective constructs, we examined the internal consistency reliability, indicator reliability, convergent validity, and discriminant validity [106]. For each construct, Cronbach's $\alpha$ was higher than 0.76 , the composite reliability was higher than 0.85 , and average variance extracted (AVE) was greater than 0.54 , exceeding the recommended thresholds of internal consistency reliability and convergent validity 
[33], [106]. All indicators loaded strongly on their intended constructs, suggesting sufficient indicator reliability. The loading of each indicator was higher for the intended constructs than for any other constructs, and each construct loaded most strongly with its own indicators, suggesting adequate discriminant validity. Each construct's AVE was greater than the construct's highest squared correlation with any other construct, indicating sufficient discriminant validity [33].

We conducted two confirmatory factor analyses. The first confirmatory factor analysis includes all dependent variables, including coordination effectiveness, coordination cost, project effectiveness (meeting requirements and changing requirements), and project efficiency. The analysis reveals acceptable fit $\left(\chi^{2}=268.52\right.$, root mean square error of approximation $[$ RMSEA $]=0.07$, confirmatory fit index $[\mathrm{CFI}]=0.90$ ). The second confirmatory factors analysis features all independent variables toward project performance, including process rigor, process standardization, coordination effectiveness, coordination cost, and task routinization. The analysis reveals an acceptable fit $\left(\chi^{2}=312.03\right.$, RMSEA $\left.=0.07, \mathrm{CFI}=0.90\right)$. The above examinations suggest that the reflective measures were reliable and valid.

In this study, we focus on the effects of SDPA rather than on the effects of sub-dimensions of process alignment and process adaptability. Thus, we used the aggregated values of the respective indicators to represent the two constructs and used the product between the two to represent SDPA [34]. We assessed the validity of the formative constructs with principal component analysis [75]. For process alignment, one single factor with an eigenvalue greater than 1 was extracted, accounting for $53.4 \%$ of the variance. The weights of all the indicators were greater than 0.56 , suggesting high indicator validity [106]. For project effectiveness, the intended two-factor model emerged with a varimax rotation. The two factors accounted for $70.3 \%$ of the variance with very high indicator validity.

For process adaptability, two factors with eigenvalues greater than 1 were extracted with a varimax rotation, accounting for $40.6 \%$ of the variance. All the weights were greater than 0.49 , exceeding the recommended threshold [14]. The highest variance inflation factor (VIF) of all the indicators for process adaptability was 1.5 , suggesting very low indicator redundancy [75]. To examine the nomological validity [106], we linked the formative construct to a single-indicator construct describing whether agile development methods were adopted in the project. The two constructs were strongly and significantly correlated (path coefficient $=0.50, t=11.72, p$ $<0.001$ ), indicating high nomological validity. Finally, we examined the discriminant validity by checking inter-construct correlations. The highest correlation between process adaptability and other constructs was 0.59 , lower than the threshold [106], suggesting sufficient discriminant validity.

\subsection{Post-Hoc Analyses}

During the questionnaire design and data collection, we adopted multiple techniques to reduce common method biases [60], [77]. These techniques include randomizing the question order within each questionnaire page, protecting respondent anonymity, collecting partial factual data on project efficiency, measuring coordination costs with a Likert-type scale and a ratio scale, and aggregating individual responses to the project level.

In the post-hoc data analysis, we conducted three tests to examine the magnitude of common method bias. First, we performed Harman's single-factor test [77] by including all the study variables in a principle component factor analysis. The result revealed that the first factor accounts for $21.0 \%$ of the variance in the dataset, indicating that a dominant single factor did not exist in the data. Second, we added the first unrotated factor into the model as a control factor on all mediators and dependent variables. This factor is assumed to have the best approximation of common method variance [77]. Including this factor in the model did not significantly increase the explained variance of any mediator or dependent variable (average increase $=0.013$ ), suggesting very low common method bias. Third, we used the marker variable approach [57] and added a theoretically unrelated marker variable into the model. We used whether German language was chosen as the common language in the project team as a marker variable. Controlling for the marker variable, the largest change in the correlations of the study variables was 0.003 , suggesting very low common method bias. Thus, we conclude that common method bias is not a major concern in the collected data.

\section{Model Estimation And Results}

We estimate our model using regression analysis with hierarchical linear regression and multiple mediator analysis [38], [78]. We start with a model including our controls only. Following the guidelines by Baron and Kenny [6] and further advancements [38], [110], we estimate four additional models in order to test for mediation effects. These four models estimate: (1) the correlation between SDPA and performance $(\mathrm{H} 1 \mathrm{a} / \mathrm{b}),(2)$ the correlation between SDPA and coordination $(\mathrm{H} 2 \mathrm{a} / \mathrm{b})$, (3) the correlation between coordination effectiveness $(\mathrm{H} 3 \mathrm{a} / \mathrm{b})$, coordination cost $(\mathrm{H} 4 \mathrm{a} / \mathrm{b})$ and performance, and (4) the model including all variables toward performance. Thereafter, we test our hypotheses about the mediating effects of coordination for both dependent variables using multiple mediator analysis [79], [92]. Table 1 presents the descriptive statistics and intercorrelations of the study variables in the research model. All the metric variables satisfied the assumption of normality. All correlations are below 0.70 , and the largest VIF of the independent variables was 2.42, both indicating that multicollinearity is no concern [86].

\subsection{Analysis of Direct Effects}

First, we estimate our models testing the association with project effectiveness. Then, we test the corresponding models toward project efficiency. Tables 2 and 3 present the results of the hierarchical regression analysis for project effectiveness and project efficiency. Both tables include models presenting the relationship between SDPA and coordination cost/effectiveness. 
TABLE 1

DESCRIPTIVE STATISTICS AND CORRELATIONS (PROJECT-LEVEL ANALYSIS, N=104)

\begin{tabular}{|c|c|c|c|c|c|c|c|c|c|c|c|}
\hline \multirow{2}{*}{ Variable } & \multirow{2}{*}{ Mean } & \multirow{2}{*}{ SD } & \multicolumn{9}{|c|}{ Correlation coefficients } \\
\hline & & & 1 & 2 & 3 & 4 & 5 & 6 & 7 & 8 & 9 \\
\hline 1. Process ambidexterity & 21.97 & 6.75 & & & & & & & & & \\
\hline 2. Coord. effectiveness & 5.13 & 0.70 & $0.69^{* * *}$ & & & & & & & & \\
\hline 4. Project efficiency & 3.96 & 1.64 & 0.18 & $0.29^{* * *}$ & $-0.21^{*}$ & & & & & & \\
\hline 5. Project effectiveness & 5.26 & 0.73 & $0.52^{* * *}$ & $0.49^{* * *}$ & 0.14 & $0.27^{* * *}$ & & & & & \\
\hline 8. Team distribution [time zones] & 2.12 & 1.31 & -0.05 & -0.01 & $0.21^{*}$ & -0.03 & -0.04 & $0.34^{* * *}$ & $0.80^{* * *}$ & & \\
\hline 9. Team distribution [time span] & 3.27 & 3.05 & 0.03 & -0.05 & $0.23^{*}$ & -0.12 & -0.16 & $0.44^{* * *}$ & $0.64^{* * *}$ & $0.59^{* * *}$ & \\
\hline 10. Task routineness & 3.89 & 1.12 & -0.01 & -0.10 & -0.01 & -0.11 & $-0.22^{*}$ & 0.18 & 0.10 & 0.07 & 0.05 \\
\hline
\end{tabular}

Note: ${ }^{*} p<0.05,{ }^{* *} p<0.01,{ }^{* * *} p<0.001$

TABLE 2

SUMMARY OF HIERARCHICAL REGRESSION ANALYSIS FOR PROJECT EFFECTIVENESS ( $\mathrm{N}=104)$

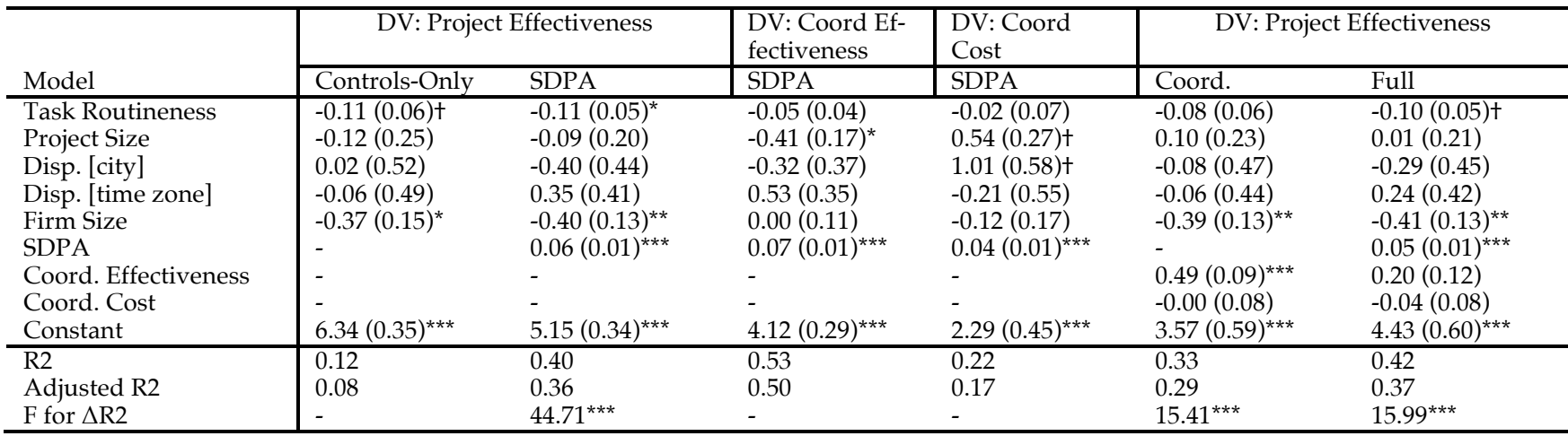

Note: 1 ) the table gives standardized coefficients (and standardized errors); 2 ) $+p<0.10,{ }^{*} p<0.05,{ }^{* *} p<0.01,{ }^{* * *} p<0.001 ; 3$ ) DV $=$ Dependent variable; 4)

Disp. = Team dispersion; 5) $S D P A=S D$ process ambidexterity; 6) Coord $=$ Coordination

TABLE 3

SUMMARY OF HIERARCHICAL REGRESSION ANALYSIS FOR PROJECT EFFICIENCY $(\mathrm{N}=104)$

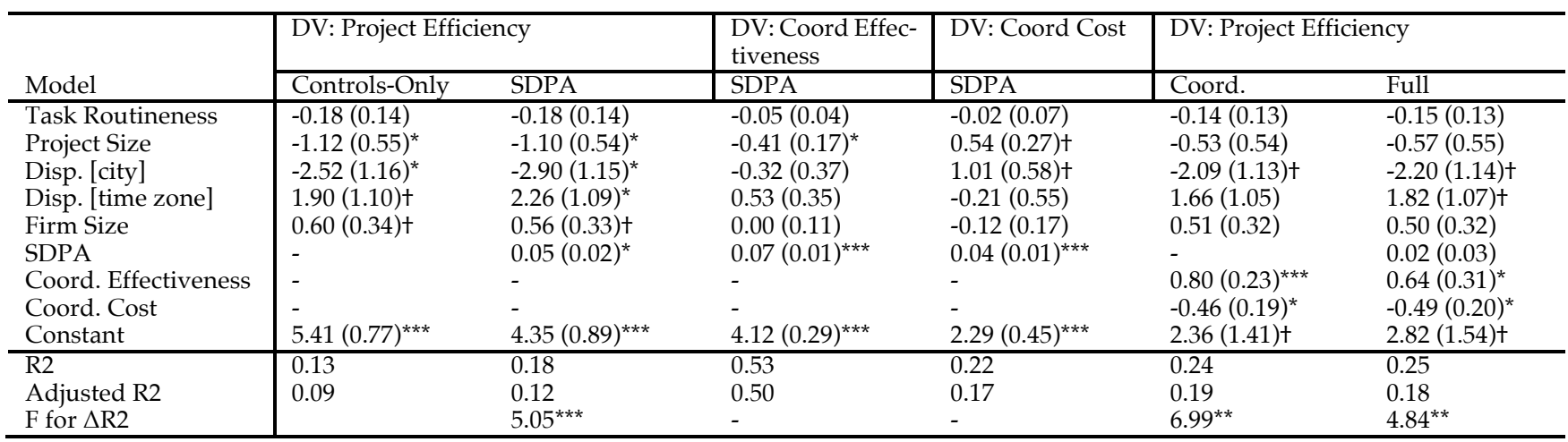

Note: 1 ) the table gives standardized coefficients (and standardized errors); 2 ) $\left.+p<0.10,{ }^{*} p<0.05,{ }^{* *} p<0.01,{ }^{* * *} p<0.001 ; 3\right)$ DV $=$ Dependent variable; 4 ) Disp. = Team dispersion; 5) SDPA $=S D$ process ambidexterity; 6) Coord. $=$ Coordination

While task routineness shows a significant effect toward project effectiveness, project size, team dispersion, and task routineness show significant effects toward project efficiency. Firm size shows significant effects toward both performance dimensions. These effects reflect prior expectations to include the variables as important controls. Nonsignificant effects of control variables can be attributed to the fact that these have not been tested in a single model simultaneously.
In step two, we include the direct effect of SDPA. The results suggest that SDPA positively correlates with project effectiveness $(\mathrm{p}<0.001)$ and project efficiency $(\mathrm{p}<0.05)$, and these effects exist over and beyond the influences of firm size, relevant project team characteristics (e.g., project size, number of cities, number of time zones), and task characteristics (i.e., task routineness).

In step three, we test the direct effect of SDPA toward coordination effectiveness and coordination cost. We find 
signification effects of SDPA in both models ( $<<0.001$ ). While project size is an important control toward coordination effectiveness and coordination cost, team dispersion (number of cities) shows significant effects in the model toward coordination cost.

In step four, we test the direct effects of coordination effectiveness and coordination cost toward both performance dimensions. We find significant relationships for coordination effectiveness toward project effectiveness $(p<0.001)$ and project efficiency $(\mathrm{p}<0.001)$. For coordination costs, we find a significant relationship toward project efficiency $(\mathrm{p}<$ 0.05 ). These effects exist while accounting for our control variables.

In step five, we test a model that includes all our variables. When predicting project effectiveness, we find significant effect from SDPA $(\mathrm{p}<0.001)$. When predicting project efficiency, we find significant effects from coordination effectiveness $(p<0.001)$ and coordination cost $(p<0.05)$.

TABLE 4

OVERVIEW OF HYPOTHESES TEST RESULTS

\begin{tabular}{l|l|l}
\hline Hypotheses & Relationship & Results \\
\hline $\mathrm{H} 1 \mathrm{a}$ & $\begin{array}{l}\text { SD process ambidexterity }-> \\
\text { Project effectiveness } \\
\text { SD process ambidexterity } \rightarrow>\end{array}$ & Supported \\
$\mathrm{H} 1 \mathrm{~b}$ & $\begin{array}{l}\text { Project efficiency } \\
\text { SD process ambidexterity }-> \\
\text { Coordination effectiveness } \\
\mathrm{H} 2 \mathrm{a}\end{array}$ & $\begin{array}{l}\text { Suppored } \\
\text { Coordination cost }\end{array}$ \\
$\mathrm{H} 2 \mathrm{~b}$ & $\begin{array}{l}\text { Coordination effectiveness }-> \\
\text { Project effectiveness } \\
\text { Coordination effectiveness }->\end{array}$ & Supported \\
$\mathrm{H} 3 \mathrm{a}$ & $\begin{array}{l}\text { Project efficiency } \\
\text { Coordination cost }->\end{array}$ & Supported \\
$\mathrm{H} 3 \mathrm{~b}$ & $\begin{array}{l}\text { Project effectiveness } \\
\text { Coordination cost }->\end{array}$ & Not Supported \\
$\mathrm{H} 4 \mathrm{a}$ & Project efficiency & Supported \\
$\mathrm{H} 4 \mathrm{~b}$ & \multicolumn{2}{|l}{} \\
\hline
\end{tabular}

\subsection{Analysis of Mediating Effects}

Next, we examine the mediating role of coordination effectiveness and coordination costs using multiple mediator analysis [38], [78]. To examine the strengths of the mediating effects, we employ bootstrapping. Bootstrapping does not impose the assumption of normality on the tested effects and is recommended as "the most powerful and reasonable method of obtaining confidence limits for specific indirect effects under most conditions" (p. 886) [78].

On the path between process ambidexterity and project effectiveness, a different result was presented. After including coordination effectiveness and coordination costs as mediators, the direct effect of process ambidexterity on project effectiveness only slightly dropped (see Figure 2), indicating a partial mediating effect. Tested with bootstrapping with 5000 samples, the $95 \%$ CI of the indirect effect of coordination effectiveness on project effectiveness is [-0.002, 0.039], and the $95 \% \mathrm{CI}$ of the indirect effect of coordination costs on project efficiency is $[-0.009,0.004]$. Tested with the Sobel test [92], the mediating effect of coordination effectiveness was moderately significant $(p=0.03)$, and the mediating effect of coordination costs was not significant ( $p=0.53$ ). These findings indicate that the relationship between SDPA and project effectiveness is positively mediated (complementary) by coordination effectiveness, but not by coordination costs (direct-only).

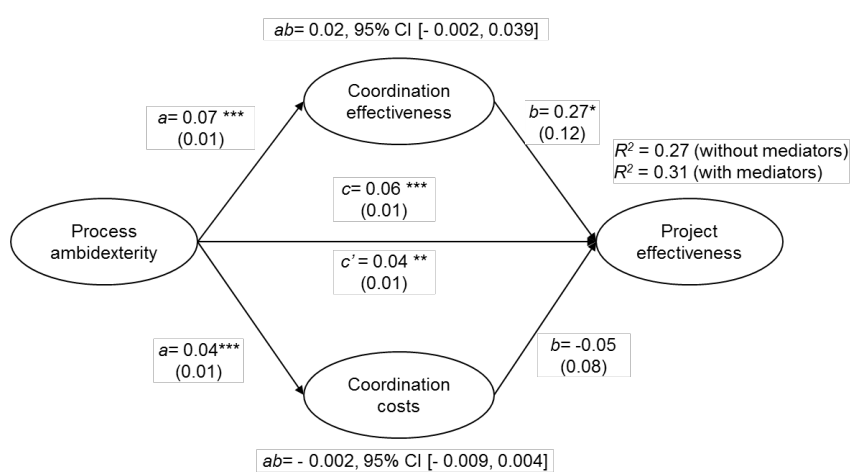

Note: 1$\left.){ }^{*} p<0.05,{ }^{* * *} p<0.001 ; 2\right)$ bias corrected confidence intervals are calculated

Fig. 2. Mediating effects of coordination on the path between process ambidexterity and project effectiveness.

As depicted in Figure 3, after including coordination effectiveness and coordination costs, the direct effect of process ambidexterity on project efficiency dropped significantly, suggesting a mediating effect. Bootstrapping with 5000 samples, the $95 \% \mathrm{CI}$ of the indirect effect of coordination effectiveness on project efficiency is $[0.02,0.10]$ and the $95 \% \mathrm{CI}$ of the indirect effect of coordination costs on project efficiency is [-0.05, -0.01]. Tested with the Sobel test [92], both indirect effects are significant at 0.05 level (Coordination effectiveness: $p=0.008$, coordination costs: $p=0.016$ ). These results suggest that the mediating effects of coordination effectiveness within the relationship between process ambidexterity and process efficiency is positive, whereas the mediating effects of coordination costs within the same relationship is negative. The two factors together fully mediate the relationship between process ambidexterity and project efficiency (indirect-only). An overview of all tested hypotheses and their results is shown in Table 4.

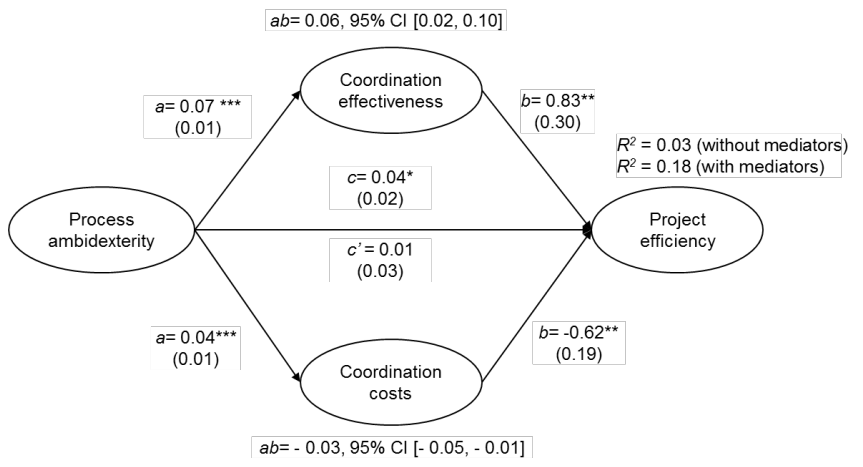

Note: 1$\left.){ }^{* *} p<0.01,{ }^{* * *} p<0.001 ; 2\right)$ bias corrected confidence intervals are calculated

Fig. 3. Mediating effects of coordination on the path between process ambidexterity and project efficiency.

\section{Discussion}

While prior studies support the association between SDPA and SD project performance, the results are inconclusive (cf. [48], [49]) and empirical research investigating fine- 
granular mechanisms is lacking [43], [89]. Drawing on organizational theory, this study understands SDPA and coordination as dynamic capabilities. The mediating role of coordination in the relationship between SDPA and aspects of project performance is tested using data from $104 \mathrm{SD}$ projects. The results suggest significant effects between SDPA and both coordination dimensions, supporting our theoretical view that SDPA is the nature of and coordination is the action of dynamic capability. Therefore, managing project alignment and adaptability helps the project team to coordinate dependencies more effective. In line with prior research suggesting the resource demand of ambidexterity [29], SDPA also increases coordination cost.

\subsection{Mediating Effects of Coordination}

The mediating effects of coordination on the relationship between SDPA and project performance are investigated. Thus, this study addresses the need to investigate mediators within the association between ambidexterity and performance [81], [89]. We find evidence that the effects of SDPA are mediated by coordination effectiveness and coordination costs. These findings support our underlying theoretical lens that coordination is an important action that forms a dynamic capability and mediates the effects of SDPA onto the project's performance [49], [80], [94].

The results suggest significant mediating effects of coordination effectiveness on both project performance aspects. These findings suggest that the additional coordination efforts help ambidextrous SD projects to incorporate changes and to respond to changes while simultaneously enabling on-time delivery and within the specified budget. The results suggest the possibility that organizations may shift their focus from addressing tradeoffs between efficiency and effectiveness to using coordination effectiveness to help increase the combined levels of both project efficiency and project effectiveness. This was conceptualized by Cao et al. [19] as the combined dimension that contrasts with the balance dimension of ambidexterity, which has received much attention in the literature. Cao et al. [19] argue that there are conditions under which two apparently conflicting goals (e.g., exploration and exploitation) may be complementary to one another. Our findings suggest a further examination of the conditions in which coordination effectiveness may create complementarities between efficiency and effectiveness. This is also consistent with the role of environmental munificence explored by Cao et al. [19], in that the environmental conditions help organizations "grow the pie" in addition to addressing tradeoffs. Thus, SDPA helps projects manage and cope with the increased complexity of coordination during the SD process and benefit from it, affecting project quality and on-time/in-budget completion [48].

The mediating effect of coordination effectiveness in the relationship between SDPA and project effectiveness is in line with our expectations. Additional coordination efforts and synchronization efforts help project teams incorporate initial requirements and to respond to additional changes throughout the project lifecycle [68]. Hence, SD project managers following an ambidextrous strategy should ensure the synchronization of project activities and ensure that resources are shared fairly across the team members to gain performance benefits. Regarding coordination costs, we find a significant mediating effect in the relationship between SDPA and project efficiency and a non-significant mediating effect in the relationship between SDPA and project effectiveness. Both mediating effects decrease project efficiency, matching our expectation. Spending more time and efforts on coordination increases the project cost and thus, decreases project efficiency [30].

\subsection{Effects of the Cost-Effectiveness View}

Considering the effects of coordination effectiveness and coordination costs jointly, the study supplements existing literature on SDPA with a coordination cost-effectiveness view, resolving prior conflicting results. This balanced view is particularly valuable, as it highlights that SDPA influences project performance through two opposing mechanisms: improving coordination effectiveness, which improves project performance, and increasing coordination costs, which reduces project efficiency. Based on the costeffectiveness view, SDPA improves project performance only when process gains are larger than process losses [101]. Our results suggest that the net-effect of the full model including the cost-effectiveness view improves the explanatory power toward project performance with an overall fit of OLS $R^{\wedge} 2=0.28$ and McElroy $R^{\wedge} 2=0.33$. These improvements remain significant when comparing to the SDPA model with the full model for project effectiveness $(\mathrm{F}=15.99 ; \mathrm{p}<0.001)$ and project efficiency $(\mathrm{F}=4.84 ; \mathrm{p}<$ 0.01 ). Hence, SD managers should prioritize the coordination work and results, in contrast to the efforts and time spend on these activities. In addition, coordination activities that require a minimal time investment can play an important role in achieving high project performance.

\subsection{Validation of Research Results}

To validate our research results and their practical implications, we conducted a case study in an organization that employs several hundred IT professionals. Following prior guidelines for qualitative methods [87] and examples of qualitative analysis in Software Engineering [1], we conducted semi-structured on-site and telephone interviews. The interviews focused on the respondents' experience with recent projects that sought to achieve both process alignment and process adaptability. The study respondents included project managers (PM), project directors, team leads, and a Vice President (VP). Each interview was conducted by a senior researcher with extensive experience in conducting qualitative studies and lasted from 45 to 80 minutes. Table 5 provides details on the participants.

TABLE 5

OVERVIEW OF INTERVIEW PARTICIPANTS

\begin{tabular}{l|c|c}
\hline Role & $\begin{array}{c}\text { Number of inter- } \\
\text { views }\end{array}$ & $\begin{array}{c}\text { Average IT Ex- } \\
\text { perience }\end{array}$ \\
\hline Project manager & 10 & 11 \\
\hline Project director & 6 & 14 \\
\hline Team lead & 4 & 8 \\
\hline Vice President & 3 & 17 \\
\hline
\end{tabular}


The organization strived to achieve a balance between meeting customer requirements that evolved over time and following a disciplined process. "For our development process to be scalable and meet our deployment standards we had to use a rigorous process but at the same time we need to be able to respond to rapidly changing needs of our customers," explained a VP who manages a large portfolio of projects. "Our teams were required to follow our standards that we have clearly defined, but we have to also give them some flexibility because it is important for them to accommodate our customers. Our customers are operating in a business climate where their own needs are changing, sometimes quite significantly, even over the course of the project," he elaborated. He stated that "After a lot of tweaking, we are in fact able to achieve both these goals." Towards both goals, the organization has developed ambidextrous practices that balance the need for flexibility with a disciplined process. For example, "We organized the team in such a way that each team member was given a leadership role in shaping the direction of the project but from specific parts of a product roadmap. This joint ownership helped the team work effectively as a single unit, but within the broad goals we had established in the roadmap," explained a VP.

A project director explained how this ambidextrous process helped achieve effective coordination among team members: "Our process now provides the structure and guidelines that our team members need to work effectively with each other. And it also provides them necessary flexibility to make sure that they can collectively produce deliverables that are in sync and well-coordinated". "While some of my team members are working hard to make sure that the changes the customer wants are incorporated as early as possible in the next version of the product, they have to coordinate with the rest of the team to make sure that this integration does not negatively impact the functionality that other customers need," stated a PM. A director elaborated how the process alignment achieved through codification of processes helped in coordination. "A common understanding of the processes helped more readily monitor and evaluate outcomes." A specific practice that facilitated coordination among the subgroups involves designating team leads to serve as sentries and guards of communication. The organization supported its ambidextrous process with investments in dashboards that help track performance and deliverables, continuous integration tools that track how the code is continuously evolving, and tools that help organize and track planning tasks, development tasks, user stories, open issues, resolution of issues, etc.

However, the respondents also noted that the adapted (ambidextrous) process also increased the costs associated with achieving coordination. The same practices identified earlier that improved coordination effectiveness, also increased the time and effort spent in coordination activities. A PM further elaborated: "We needed significant coordination to make sure technical requirements that crosscut the modules were met." A team lead elaborated on the impact of her role as a sentry (facilitating and filtering information coming in) and a guard (controlling the outflow of information and resources) on coordination costs. She explained, "I had to make sure that knowledge about critical dependencies across the work done by the sub-teams are well understood, but not over- whelm members with unnecessary information. This indeed occupied much of my schedule." The need to assign project personnel to facilitating coordination was a significant concern for a project manager: "My project leads were spending a lot of time just doing gate keeping rather than actively engaging in delivering the project."

There was widespread recognition that effective coordination was facilitated by the ambidextrous practices and helped the organization meet customer needs very effectively. "Since we are all working well together and are coordinating our tasks a lot better than ever before, we are a lot more successful in delivering the product that the customer wants, even though what they want is often changing during the course of the project," explained a director. "We used to work in cross purposes, but with the new process we are like a well-oiled machine working in sync; we can quickly adapt to changes that the customer wants and deliver," stated a project lead. While the costs associated with coordination was mentioned as a concern, the informants assessment suggested limited impact on project effectiveness. "Even though we had to devote a lot of effort, especially with team leads spending a lot of their time helping the teams working well together, it was worth it. All of this helped us avoid a lot of rework that we would have done otherwise," explained a PM. "More and more of our projects involve closely working with the customer to understand how their requirements are changing so that we can deliver the functionality they need. All the investments we put into making sure that the entire team is well aligned to make this happen have been very worthwhile for us," stated a director.

The PMs commented on the need to balance the impact of coordination effectiveness and coordination costs on project efficiency. They suggested that well-coordinated teams perform better in meeting budgets and schedule goals. "When all of our deliverables are in sync and everyone pays attention to what other team members need from them, the project gets completed in a timely manner and we also save a lot of work that we would otherwise have done during integration" stated a PM. "The process we now have in place makes sure that we don't waste a lot of time and money in rework. Obviously, this helps in keeping the project on schedule and within budget," elaborated another PM. However, the costs incurred in achieving coordination were not insignificant. According to a director, these costs do have a bearing on the total cost of the project as well as its schedule. "Our middle tier makes a lot of effort in to make sure everyone works well with each other and the customer. This is definitely an overhead that has to come out of the project budget. Also, because a lot of time is spent in this effort rather than on producing deliverables, it also has somewhat of a negative effect on the schedule," she elaborated. However, according to a VP, the net effect is a positive one on both project costs and schedule. "We are now convinced that we now have a process that helps us not only deliver what the customer needs when they need it, we are also able to meet schedule and budget expectations. Overall, it's working very well'".

\section{Limitations AND FUtURE RESEARCH}

While we collected retrospective data, we implemented different measures to mitigate any negative effect. A time 
lag between the project's completion date and the data collection could introduce a recall bias, in that the respondents may not adequately remember historic events. However, we used various methods to ensure the reported measures are reliable and valid, including drawing on validated scales from prior studies, asking respondents to focus on their most recent project, and triangulating self-reported data with actual project data. While these methods reduced the risks related to retrospective data [64], they cannot avoid them. Hence, future research using conduct a longitudinal survey to collect data on coordination effectiveness and coordination costs during the execution of a project and measure project performance with actual performance criteria (e.g., completion time, spending, number of bugs) deserves consideration.

On a related matter, we adopted a cross-sectional research design, which could not capture the dynamic changes in the effects of process ambidexterity through time. The abovementioned longitudinal study could mitigate this issue and is therefore suggested for future research. Scholars should also investigate the effects of SDPA in our study more closely. For example, while we find a strong mediation of coordination toward project efficiency, our results suggest the partial mediation of coordination toward project effectiveness.

In sum, our study develops a granular view of the relationship between SDPA and project performance by considering the mediating effects of coordination effectiveness and coordination costs. This study advances the understanding of process ambidexterity and provides theoretically justifiable and empirically grounded suggestions for $\mathrm{SD}$ practice. For example, SD project managers need to synchronize project activities and share resources fairly across team members when following an ambidextrous strategy. In addition, they should prioritize coordination work over the efforts spend on these activities. As a result, $\mathrm{SD}$ project managers will benefit from performance gains.

\section{REFERENCES}

[1] I. Abal, J. Melo, Ş. Stănciulescu, C. Brabrand, M. Ribeiro, and A Wasowski, "Variability Bugs in Highly Configurable Systems," ACM Trans. Softw. Eng. Methodol., vol. 26, no. 3, pp. 1-34, Jan. 2018.

[2] S. Ahuja and Y. E. Chan, "The Enabling Role of IT in Frugal Innovation," in International Conference on Information Systems, 2014, pp. 1-20.

[3] J. S. Armstrong and T. S. Overton, "Estimating Nonresponse Bias in Mail Surveys," J. Mark. Res., vol. 14, no. 3, pp. 396-402, 1977.

[4] R. D. Austin and L. Devin, "Weighing the benefits and costs of flexibility in making software: Toward a contingency theory of the determinants of development process design," Inf. Syst. Res., vol. 20, no. 3, pp. 462-477, 2009.

[5] J. B. Barlow et al., "Overview and guidance on agile development in large organizations," Commun. AIS, vol. 29 , no. 1, pp. 25-44, 2011.

[6] R. M. Baron and D. a. Kenny, "The moderator-mediator variable distinction in social psychological research: Conceptual, strategic, and statistical considerations.," J. Pers. Soc. Psychol., vol. 51, no. 6, pp. 1173-1182, 1986.

[7] D. Batra, W. Xia, D. VanderMeer, and K. Dutta, "Balancing agile and structured development approaches to successfully manage large distributed software projects: a case study from the cruise line industry," Commun. AIS, vol. 27, no. 1, pp. 379-394, 2010.

[8] M. J. Benner and M. L. Tushman, "Exploitation, Exploration, and Process Management: The Productivity Dilemma Revisited," Acad. Manag. Rev., vol. 28, no. 2, pp. 238-256, Apr. 2003.
[9] S. Bick, K. Spohrer, R. Hoda, A. Scheerer, and A. Heinzl, "Coordination Challenges in Large-Scale Software Development: A Case Study of Planning Misalignment in Hybrid Settings," IEEE Trans. Softw. Eng., vol. 5589, no. c, pp. 11, 2017.

[10] J. Birkinshaw, A. Zimmermann, and S. Raisch, "How Do Firms Adapt to Discontinuous Change? Bridging the Dynamic Capabilities and Ambidexterity Perspectives," Calif. Manage. Rev., vol. 58, no. 4, pp. 36-58, Aug. 2016.

[11] P. D. Bliese, "Within-group agreement, non-independence, and reliability: Implications for data aggregation and analysis," Multilevel theory, research, and methods in organizations: Foundations, extensions, and new directions. pp. 349-381, 2000.

[12] K. Blincoe, G. Valetto, and D. Damian, "Facilitating Coordination between Software Developers: A Study and Techniques for Timely and Efficient Recommendations," IEEE Trans. Softw. Eng., vol. 41, no. 10, pp. 969-985, Oct. 2015.

[13] B. W. Boehm and R. Turner, "Balancing agility and discipline: Evaluating and integrating agile and plan-driven methods," in Proceedings of the 26th International Conference on Software Engineering, 2004, pp. 718-719.

[14] N. A. Bonner, "Acceptance of systems development methodologies: Testing a theoretically integrated model," Doctoral Dissertation, University of Texas, Arlington, TX, USA, 2008.

[15] M. Brettel, F. Heinemann, A. Engelen, and S. Neubauer, “Crossfunctional integration of R\&D, marketing, and manufacturing in radical and incremental product innovations and its effects on project effectiveness and efficiency," J. Prod. Innov. Manag., vol. 28, no. 2, pp. 251-269, 2011

[16] R. D. Brown and N. M. A. Hauenstein, "Interrater Agreement Reconsidered: An Alternative to the rwg Indices," Organ. Res. Methods, vol. 8, no. 2, pp. 165-184, Apr. 2005.

[17] R. A. Burgelman, "Intraorganizational Ecology of Strategy Making and Organizational Adaptation: Theory and Field Research," Organ. Sci., vol. 2, no. 3, pp. 239-262, Aug. 1991.

[18] L. Cao, K. Mohan, B. Ramesh, and S. Sarkar, "Evolution of Governance: Achieving Ambidexterity in IT Outsourcing," J. Manag. Inf. Syst., vol. 30, no. 3, pp. 115-140, Jan. 2013.

[19] Q. Cao, E. Gedajlovic, and H. Zhang, "Unpacking Organizational Ambidexterity: Dimensions, Contingencies, and Synergistic Effects," Organ. Sci., vol. 20, no. 4, pp. 781-796, Aug. 2009.

[20] A. Carmeli and M. Y. Halevi, "How top management team behavioral integration and behavioral complexity enable organizational ambidexterity: The moderating role of contextual ambidexterity," Leadersh. Q., vol. 20, no. 2, pp. 207-218, Apr. 2009.

[21] M. Cataldo and J. D. Herbsleb, "Coordination Breakdowns and Their Impact on Development Productivity and Software Failures," IEEE Trans. Softw. Eng., vol. 39, no. 3, pp. 343-360, Mar. 2013.

[22] S. R. Cellini and J. E. Kee, "Cost-effectiveness and cost-benefit analysis," in Handbook of Practical Program Evaluation, 3rd ed., J. S. Wholey, H. P. Hatry, and K. E. Newcomer, Eds. San Francisco: Jossey-Bass, 2010, pp. 493-530.

[23] G. A. Churchill, "A Paradigm for Developing Better Measures of Marketing Constructs," J. Mark. Res., vol. 16, no. 1, p. 64, Feb. 1979.

[24] D. J. Collis, "How Valuable Are Organizational Capabilities?," Strateg. Manag. J., vol. 15, pp. 143-152, 1994.

[25] J. N. Cummings, J. A. Espinosa, and C. K. Pickering, "Crossing Spatial and Temporal Boundaries in Globally Distributed Projects: A Relational Model of Coordination Delay," Inf. Syst. Res., vol. 20, no. 3, pp. 420-439, Sep. 2009.

[26] J. N. Cummings and S. Kiesler, "Coordination costs and project outcomes in multi-university collaborations," Res. Policy, vol. 36, no. 10, pp. 1620-1634, Dec. 2007.

[27] J. A. Dixon, K. Brohman, and Y. Chan, "Dynamic Ambidexterity: Exploiting Exploration for Digital Business Success," ICIS 2017 Proc., no. 1996, pp. 1-17, 2017.

[28] R. Duncan, "The ambidextrous organization: Designing dual structures for innovation," in The management of organization, New York, NY, USA: North-Holland, 1976, pp. 167-188.

[29] J. J. Ebben and A. C. Johnson, "Efficiency, flexibility, or both? Evidence linking strategy to performance in small firms," Strateg. Manag. J., vol. 26, no. 13, pp. 1249-1259, Dec. 2005.

[30] J. A. Espinosa, J. N. Cummings, and C. Pickering, "Time Separation, Coordination, and Performance in Technical Teams," IEEE Trans. Eng. Manag., vol. 59, no. 1, pp. 91-103, Feb. 2012. 
[31] J. A. Espinosa and C. Pickering, "The Effect of Time Separation on Coordination Processes and Outcomes: A Case Study," in Proceedings of the 39th Hawaii International Conference on System Sciences, 2006, pp. 191-209.

[32] S. Faraj and L. Sproull, "Coordinating Expertise in Software Development Teams," Manage. Sci., vol. 46, no. 12, pp. 15541568,2000

[33] C. Fornell and D. F. Larcker, "Evaluating Structural Equation Models with Unobservable Variables and Measurement Error," J. Mark. Res., vol. 18, no. 1, p. 39, Feb. 1981.

[34] C. B. Gibson and J. Birkinshaw, "THE ANTECEDENTS, CONSEQUENCES, AND MEDIATING ROLE OF ORGANIZATIONAL AMBIDEXTERITY.," Acad. Manag. J., vol. 47, no. 2, pp. 209-226, Apr. 2004.

[35] A. Gopal, J. A. Espinosa, S. Gosain, and D. P. Darcy, "Coordination and Performance in Global Software Service Delivery: The Vendor's Perspective," IEEE Trans. Eng. Manag., vol. 58, no. 4, pp. 772-785, Nov. 2011

[36] R. W. Gregory and M. Keil, "Blending bureaucratic and collaborative management styles to achieve control ambidexterity in IS projects," Eur. J. Inf. Syst., vol. 23, no. 3, pp. 343-356, May 2014.

[37] R. W. Gregory, M. Keil, J. Muntermann, and M. Mähring, "Paradoxes and the Nature of Ambidexterity in IT Transformation Programs," Inf. Syst. Res., vol. 26, no. 1, pp. 5780, Mar. 2015

[38] A. F. Hayes, "Beyond Baron and Kenny: Statistical Mediation Analysis in the New Millennium," Commun. Monogr., vol. 76, no. 4, pp. 408-420, Dec. 2009.

[39] J. D. Herbsleb and A. Mockus, "An empirical study of speed and communication in globally distributed software development," IEEE Trans. Softw. Eng., vol. 29, no. 6, pp. 481-494, Jun. 2003.

[40] G. Im and A. Rai, "IT-Enabled Coordination for Ambidextrous Interorganizational Relationships," Inf. Syst. Res., vol. 25, no. 1 pp. 72-92, Mar. 2014.

[41] L. R. James, "Aggregation bias in estimates of perceptual agreement.," J. Appl. Psychol., vol. 67, no. 2, pp. 219-229, 1982.

[42] M. Joblin, S. Apel, and W. Mauerer, "Evolutionary trends of developer coordination: a network approach," Empir. Softw. Eng., vol. 22, no. 4, pp. 2050-2094, Aug. 2017

[43] P. Junni, R. M. Sarala, V. Taras, and S. Y. Tarba, "Organizational Ambidexterity and Performance: A Meta-Analysis," Acad. Manag. Perspect., vol. 27, no. 4, pp. 299-312, Nov. 2013.

[44] A. Kathuria and B. R. Konsynski, "Juggling Paradoxical Strategies: The Emergent Role of IT Capabilities," in International Conference on Information Systems, 2012, p. Paper 10.

[45] J. Kietzmann, K. Plangger, B. Eaton, K. Heilgenberg, L. Pitt, and P. Berthon, "Mobility at work," J. Strateg. Inf. Syst., vol. 22, no. 4, pp. 282-297, Dec. 2013

[46] W. King and J. He, "External validity in IS survey research," Commun. Assoc. Inf. Syst., vol. 16, no. 1, pp. 880-894, 2005

[47] J. M. LeBreton and J. L. Senter, "Answers to 20 Questions About Interrater Reliability and Interrater Agreement," Organ. Res. Methods, vol. 11, no. 4, pp. 815-852, Nov. 2007.

[48] G. Lee, W. DeLone, and J. A. Espinosa, "Ambidextrous coping strategies in globally distributed software development projects," Commun. ACM, vol. 49, no. 10, p. 35, 2006.

[49] G. Lee, W. H. DeLone, and J. A. Espinosa, "The main and interaction effects of process rigor, process standardization, and process agility on system performance in distributed IS development: An ambidexterity perspective," in International Conference on Information Systems, 2010, p. Paper 34

[50] G. Lee, J. A. Espinosa, and W. H. DeLone, "Balancing rigor, standardization, and agility in distributed IS development process: An ambidexterity perspective (working paper)," American University, Washington, DC, Apr. 2012.

[51] G. Lee, J. A. Espinosa, and W. H. DeLone, "The effect of process ambidexterity on the success of distributed information systems development," in Proceedings of the Academy of Management Annual Meeting, 2009, pp. 1-6.

[52] G. Lee, J. A. Espinosa, and W. H. DeLone, "Task Environment Complexity, Global Team Dispersion, Process Capabilities, and Coordination in Software Development," IEEE Trans. Softw. Eng., vol. 39, no. 12, pp. 1753-1771, Dec. 2013

[53] G. Lee and W. Xia, "Toward agile: an integrated analysis of quantitative and qualitative field data on software development agility," Manag. Inf. Syst. Q., vol. 34, no. 1, pp. 87-114, 2010

[54] T. Lee, J. Nam, D. Han, S. Kim, and H. Peter In, “Developer Micro Interaction Metrics for Software Defect Prediction," IEEE Trans.
Softw. Eng., vol. 42, no. 11, pp. 1015-1035, Nov. 2016.

[55] M. W. Lewis, "EXPLORING PARADOX: TOWARD A MORE COMPREHENSIVE GUIDE.," Acad. Manag. Rev., vol. 25, no. 4, pp. 760-776, Oct. 2000.

[56] Z. Lin, H. Yang, and I. Demirkan, "The Performance Consequences of Ambidexterity in Strategic Alliance Formations: Empirical Investigation and Computational Theorizing," Manage. Sci., vol. 53, no. 10, pp. 1645-1658, Oct. 2007.

[57] M. K. Lindell and D. J. Whitney, "Accounting for common method variance in cross-sectional research designs.," J. Appl. Psychol., vol. 86, no. 1, pp. 114-121, 2001.

[58] J. R. Lindner, T. H. Murphy, and G. E. Briers, "Handling Nonresponse In Social Science Research," J. Agric. Educ., vol. 42, no. 4, pp. 43-53, Dec. 2001.

[59] K. Lyytinen and G. M. Rose, "Information system development agility as organizational learning," Eur. J. Inf. Syst., vol. 15, no. 2, pp. 183-199, Apr. 2006.

[60] S. B. MacKenzie and P. M. Podsakoff, "Common Method Bias in Marketing: Causes, Mechanisms, and Procedural Remedies," J. Retail., vol. 88, no. 4, pp. 542-555, Dec. 2012.

[61] T. W. Malone, "Modeling Coordination in Organizations and Markets," Manage. Sci., vol. 33, no. 10, pp. 1317-1332, Oct. 1987.

[62] T. W. Malone and K. Crowston, "The interdisciplinary study of coordination," ACM Comput. Surv., vol. 26, no. 1, pp. 87-119, Mar. 1994.

[63] A. P. Massey, M. M. Montoya-Weiss, and Y.-T. Hung, “Because time matters: Temporal coordination in global virtual project teams," J. Manag. Inf. Syst., vol. 19, no. 4, pp. 129-155, 2003.

[64] C. C. Miller, L. B. Cardinal, and W. H. Glick, "Retrospective Reports in Organizational Research: a Reexamination of Recent Evidence.," Acad. Manag. J., vol. 40, no. 1, pp. 189-204, Feb. 1997.

[65] S. Mithas and R. T. Rust, "How Information Technology Strategy and Investments Influence Firm Performance: Conjecture and Empirical Evidence," MIS Q., vol. 40, no. 1, pp. 223-245, 2016.

[66] V. S. Mookerjee and I. R. Chiang, "A dynamic coordination policy for software system construction," IEEE Trans. Softw. Eng., vol. 28 , no. 7, pp. 684-694, Jul. 2002.

[67] N. P. Napier, L. Mathiassen, and D. Robey, "Building contextual ambidexterity in a software company to improve firm-level coordination," Eur. J. Inf. Syst., vol. 20, no. 6, pp. 674-690, Nov. 2011.

[68] A. Nguyen-Duc, D. S. Cruzes, and R. Conradi, "The impact of global dispersion on coordination, team performance and software quality-A systematic literature review," Inf. Softw. Technol., vol. 57, no. 1, pp. 277-294, 2015.

[69] S. Nidumolu, "The Effect of Coordination and Uncertainty on Software Project Performance: Residual Performance Risk as an Intervening Variable," Inf. Syst. Res., vol. 6, no. 3, pp. 191-219, Sep. 1995.

[70] C. A. O'Reilly and M. L. Tushman, "Ambidexterity as a dynamic capability: Resolving the innovator's dilemma," Res. Organ. Behav., vol. 28, pp. 185-206, Jan. 2008.

[71] C. A. O'Reilly, M. L. Tushman, and C. A. O'Reilly III, "The Ambidextrous Organization.," Harv. Bus. Rev., vol. 82, no. 4, pp. 74-81, Apr. 2004.

[72] E. M. Olson, J. O. C. Walker, and R. W. Ruekert, “Organizing for effective new product development: The moderating role of product innovativeness Eric M. Olson, Orville C. Walker, Jr., and Robert W. Ruekert, Journal of Marketing (January 1995), pp. 4862," J. Prod. Innov. Manag., vol. 13, no. 1, p. 76, Jan. 1996.

[73] P. a. Pavlou and O. a. El Sawy, "From IT Leveraging Competence to Competitive Advantage in Turbulent Environments: The Case of New Product Development," Inf. Syst. Res., vol. 17, no. 3, pp. 198-227, Sep. 2006.

[74] P. A. Pavlou and O. A. El Sawy, "Understanding the Elusive Black Box of Dynamic Capabilities," Decis. Sci., vol. 42, no. 1, pp. 239-273, Feb. 2011

[75] S. Petter, D. Straub, and A. Rai, "Specifying formative constructs in information systems research," Mis Q., vol. 31, no. 4, pp. 623656, 2007.

[76] J. Pfeffer and G. Salancik, The external control of organization: A resource dependence perspective. New York, NY, USA: Harper \& Row, Publishers, Inc., 1978

[77] P. M. Podsakoff, S. B. MacKenzie, J.-Y. Lee, and N. P. Podsakoff, "Common method biases in behavioral research: a critical review of the literature and recommended remedies.," J. Appl. Psychol., vol. 88, no. 5, pp. 879-903, 2003.

[78] K. J. Preacher and A. F. Hayes, "Asymptotic and resampling 
strategies for assessing and comparing indirect effects in multiple mediator models," Behav. Res. Methods, vol. 40, no. 3, pp. 879-891, Aug. 2008.

[79] K. J. Preacher and A. F. Hayes, "SPSS and SAS procedures for estimating indirect effects in simple mediation models," Behav. Res. Methods, Instruments, Comput., vol. 36, no. 4, pp. 717-731, Nov. 2004

[80] A. Protogerou, Y. Caloghirou, and S. Lioukas, "Dynamic capabilities and their indirect impact on firm performance," Ind. Corp. Chang., vol. 21, no. 3, pp. 615-647, Jun. 2012.

[81] S. Raisch and J. Birkinshaw, "Organizational Ambidexterity: Antecedents, Outcomes, and Moderators," J. Manage., vol. 34, no. 3, pp. 375-409, Jun. 2008.

[82] B. Ramesh, K. Mohan, and L. Cao, "Ambidexterity in Agile Distributed Development: An Empirical Investigation," Inf. Syst. Res., vol. 23, no. 2, pp. 323-339, Jun. 2012.

[83] R. S. Raubitschek, "Product Sequencing: Co-Evolution of Knowledge , Capabilities and Products," Strateg. Manag. J., vol. 21, no. 10, pp. 961-979, 2000.

[84] V. Rousseau and C. Aube, "Team Self-Managing Behaviors and Team Effectiveness: The Moderating Effect of Task Routineness," Gr. Organ. Manag., vol. 35, no. 6, pp. 751-781, Dec. 2010.

[85] I. Scholtes, P. Mavrodiev, and F. Schweitzer, "From Aristotle to Ringelmann: a large-scale analysis of team productivity and coordination in Open Source Software projects," Empir. Softw. Eng., vol. 21, no. 2, pp. 642-683, Apr. 2016.

[86] M. A. Schroeder, J. Lander, and S. Levine-Silverman, "Diagnosing and Dealing with Multicollinearity," West. J. Nurs. Res., vol. 12, no. 2, pp. 175-187, Apr. 1990.

[87] C. B. Seaman, "Qualitative methods in empirical studies of software engineering," IEEE Trans. Softw. Eng., vol. 25, no. 4, pp. 557-572, 1999.

[88] A. J. Shenhar, D. Dvir, O. Levy, and A. C. Maltz, "Project Success: A Multidimensional Strategic Concept," Long Range Plann., vol. 34, no. 6, pp. 699-725, Dec. 2001

[89] Z. Simsek, C. Heavey, J. F. Veiga, and D. Souder, "A Typology for Aligning Organizational Ambidexterity's Conceptualizations, Antecedents, and Outcomes," J. Manag. Stud., vol. 46, no. 5, pp. 864-894, Jul. 2009.

[90] N. . Sivasubramaniam, S. J. . Liebowitz, and C. L. . Lackman, "Determinants of new product development team performance: A meta-analytic review," J. Prod. Innov. Manag., vol. 29, no. 5, pp. 803-820, 2012.

[91] S. A. Slaughter, D. E. Harter, and M. S. Krishnan, "Evaluating the cost of software quality," Commun. ACM, vol. 41, no. 8, pp. 6773, Aug. 1998.

[92] E. Sobel, "Asymptotic Confidence Intervals for Indirect Effects in Structural Equation Models," Sociol. Methodol., vol. 13, pp. 290-312, 1982

[93] X. M. Song, R. J. Thieme, and J. Xie, "The Impact of CrossFunctional Joint Involvement Across Product Development Stages: An Exploratory Study," J. Prod. Innov. Manag., vol. 15, no. 4, pp. 289-303, Jul. 1998.

[94] G. Di Stefano, M. Peteraf, and G. Verona, "The Organizational Drivetrain: A Road To Integration of Dynamic Capabilities Research," Acad. Manag. Perspect., vol. 28, no. 4, pp. 307-327, Nov. 2014.

[95] J. Sutanto, A. Kankanhalli, and B. C. Yian Tan, "Investigating Task Coordination in Globally Dispersed Teams," ACM Trans. Manag. Inf. Syst., vol. 6, no. 2, pp. 1-31, 2015.

[96] H. Tanriverdi, P. Konana, and L. Ge, "The Choice of Sourcing Mechanisms for Business Processes," Inf. Syst. Res., vol. 18, no. 3, pp. 280-299, Sep. 2007.

[97] S. D. Teasley, L. A. Covi, M. S. Krishnan, and J. S. Olson, "Rapid software development through team collocation," IEEE Trans. Softw. Eng., vol. 28, no. 7, pp. 671-683, Jul. 2002.

[98] D. J. Teece, "Explicating dynamic capabilities: the nature and microfoundations of (sustainable) enterprise performance," Strateg. Manag. J., vol. 28, no. 13, pp. 1319-1350, Dec. 2007.

[99] D. J. Teece, G. Pisano, and A. M. Y. Shuen, “Dynamic Capabilities and Strategic Management," Strateg. Manag. J., vol. 18, no. 7, pp. 509-533, 1997.

[100]O. Temizkan and R. L. Kumar, "Exploitation and Exploration Networks in Open Source Software Development: An ArtifactLevel Analysis," J. Manag. Inf. Syst., vol. 32, no. 1, pp. 116-150, Jan. 2015.

[101]R. S. Tindale and R. Starkel, "Process Gain and Loss," in Encyclopedia of Group Processes \& Intergroup Relations, 2455 Teller Road, Thousand Oaks California 91320 United States: SAGE
Publications, Inc., 2009, p. 1048

[102] A. Tiwana, "Systems Development Ambidexterity: Explaining the Complementary and Substitutive Roles of Formal and Informal Controls," J. Manag. Inf. Syst., vol. 27, no. 2, pp. 87-126, Oct. 2010

[103] A. Tiwana, "Impact of classes of development coordination tools on software development performance," ACM Trans. Softw. Eng. Methodol., vol. 17, no. 2, pp. 1-47, 2008.

[104] N. Turner, "The Management of Ambidexterity - An Intellectual Capital Perspective," Doctoral Dissertation, University of Bath, Bath, UK, 2011.

[105]M. L. Tushman and C. A. O'Reilly, "Ambidextrous organizations: Managing evolutionary and revolutionary change," Calif. Manage. Rev., vol. 38, no. 4, pp. 8-30, 1996.

[106] N. Urbach and F. Ahlemann, "Structural equation modeling in information systems research using partial least squares," J. Inf. Technol. Theory Appl., vol. 11, no. 2, pp. 5-40, 2010.

[107] G. O. Wiredu, "Understanding the functions of teleconferences for coordinating global software development projects," Inf. Syst. J., vol. 21, no. 2, pp. 175-194, Mar. 2011.

[108] L. Xue, G. Ray, and V. Sambamurthy, "Efficiency or Innovation: How do Industry Environments Moderate the Effects of Firm's IT Asset Portfolios?," MIS Q., vol. 36, no. 2, pp. 509-528, 2012.

[109] M. Yan, A. Y. Yu, and X. Dong, “Organizational Ambidexterity Building via IT-enabled Strategic Learning and Business Learning: A Evolutionary Journey of Huawei," in International Conference on Information Systems, 2013, p. Paper 10.

[110] X. Zhao, J. G. Lynch, and Q. Chen, "Reconsidering Baron and Kenny: Myths and Truths about Mediation Analysis," J. Consum. Res., vol. 37, no. 2, pp. 197-206, Aug. 2010.

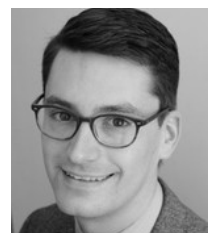

Karl Werder is a Research Fellow at the University of Cologne, Germany. He received his Doctorate Degree in Information Systems from the Karlsruhe Institute of Technology, Germany. His research focuses on software development and software-intensive businesses. His work has been published in journals, such as Information \& Software Technology, Information Technology \& People, and conferences, such as International Conference on Information Systems and Europeans Conference on Information Systems.

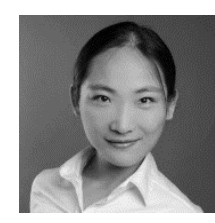

Ye $\mathbf{L i}$ is a Senior Business Enterprise Consultant at SAP SE, Germany. She received her Doctorate Degree in Information Systems at the University of Mannheim. Her research has been published in the Computers in Human Behavior, IEEE Transactions on Professional Communication, International Conference on Information Systems, European Conference on Information Systems, and others.

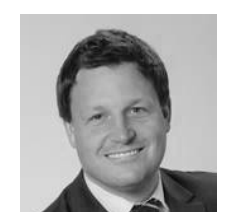

Alexander Mädche is a Full Professor of the Chair of Information Systems \& Service Design, Institute of Information Systems and Marketing at the Karlsruhe Institute of Technology. His research focuses on large-scale information systems, in particular user-centered digital transformation and user-centered intelligent systems. His work is published in leading international journals and conferences such as Journal of the Association of Information Systems, Business Process Management Journal, Information \& Software Systems Technology, IEEE Intelligent Systems, SIGMOD Record, and AI Magazine.

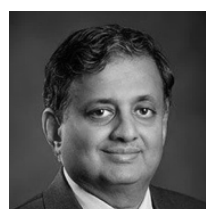

Balasubramaniam Ramesh is a Distinguished Professor, Board of Advisors Professor and Chair in Computer Information Systems, J. Mack Robinson College of Business at the Georgia State University. His research focuses on supporting knowledge intensive, complex organizational processes. His work has appeared in leading publications such as MIS Quarterly, Information Systems Research, Journal of Management Information Systems, IEEE Transactions on Software Engineering, Communications of the ACM, Journal of the AIS, Information \& Management, Requirements Engineering Journal, Annals of Operations Research, Decision Support Systems, and others. 